\title{
Marie NDiaye: l'étrangeté à l'œuvre, textes réunis par Andrew Asibong et Shirley Jordan
}

\section{Elisa Bricco}

\section{(2) OpenEdition}

1 Journals

\section{Edizione digitale}

URL: http://journals.openedition.org/studifrancesi/5779

DOI: 10.4000/studifrancesi.5779

ISSN: 2421-5856

\section{Editore}

Rosenberg \& Sellier

\section{Edizione cartacea}

Data di pubblicazione: 1 septembre 2011

Paginazione: 460-461

ISSN: 0039-2944

\section{Notizia bibliografica digitale}

Elisa Bricco, «Marie NDiaye: l'étrangeté à l'œuvre, textes réunis par Andrew Asibong et Shirley Jordan», Studi Francesi [Online], 164 (LV | II) | 2011, online dal 30 novembre 2015, consultato il 13 janvier 2021. URL: http://journals.openedition.org/studifrancesi/5779; DOI: https://doi.org/10.4000/studifrancesi. 5779

Questo documento è stato generato automaticamente il 13 janvier 2021.

\section{(c)}

Studi Francesi è distribuita con Licenza Creative Commons Attribuzione - Non commerciale - Non opere derivate 4.0 Internazionale. 


\title{
Marie NDiaye: l'étrangeté à l'œuvre, textes réunis par Andrew Asibong et Shirley Jordan
}

\author{
Elisa Bricco
}

\section{NOTIZIA}

Marie NDiaye: l'étrangeté à l'œeuvre, textes réunis par Andrew ASIBONG et Shirley JORDAN, «Revue des Sciences Humaines», 293, 2009, 215 pp.

1 Accolta come un fenomeno quando a diciotto anni pubblicò per Minuit il suo primo romanzo, Marie NDiaye ha ricevuto la giusta consacrazione nel 2009 con il prix Goncourt per Trois femmes puissantes, testo rappresentativo della sua scrittura e del suo impegno letterario. Il presente volume, il primo interamente dedicato alla scrittrice, raccoglie gli atti del convegno internazionale Autour de Marie NDiaye. Come si evince dal titolo, il tema centrale che percorre le letture risulta essere la sensazione, quasi fisica per il lettore, di essere confrontato con un mondo étrange, con situazioni apparentemente normali che celano realtà sconcertanti, dove personaggi simili a noi sviluppano comportamenti inediti e destabilizzanti. Che si tratti dunque di romanzi, ma anche di testi teatrali o di récits, NDiaye mette il lettore di fronte a una realtà intrisa di mistero e provoca uno strisciante quanto indefinito disagio.

2 I dodici saggi s'incentrano sull'analisi di precisi aspetti dell'opera di NDiaye, tuttavia alcuni assi tematici circolano da un saggio all'altro. La difficile affermazione di un'identità consapevole che caratterizza molte eroine dei romanzi, da Fanny di En famille a Rosie Carpe, a Nadia di Mon cour à l'étroit, è accompagnata dall'evidente impossibilità a stabilire rapporti umani sereni. Nora COTTILLE-FOLEY dimostra che la messa in scena di un'identità che fatica ad affermarsi va di pari passo con la rappresentazione di una realtà straniante (Les Mots pour ne pas le dire, pp.13-23). Christophe MEURÉE studia i personaggi teatrali, definiti come concavi o convessi perché 
tesi tra la cognizione di un'assenza fondamentale e il desiderio di recuperare tale assenza per dominare il prossimo (Au diable le sujet, pp. 119-136). Michael SHERINGHAM percorre Mon cour à l'étroit analizzando la rappresentazione dello spazio, che risulta essere in stretta connessione con la costruzione del personaggio principale (Espace et éthique, pp. 171-186). Il rapporto sincero e aperto con gli altri sembra impossibile per $\mathrm{i}$ personaggi ndiayani: Dominique RABATÉ si concentra sui legami affettivi che s'intrecciano in Rosie Carpe, dimostrando l'incapacità dei personaggi di relazionarsi empaticamente con gli altri (Qui peut l'entendre? Qui peut savoir?, pp. 93-100). L'amicizia è al centro dello studio di Andrew ASIBONG, Tou(te)s mes ami(e)s (pp. 137-152), che afferma l'impossibilità di questa relazione perché tormentata da pulsioni contrastanti e desideri nascosti. Christine JÉRUSALEM in Des larmes de sang au sang épuisé dans l'œuvre de Marie Ndiaye (pp. 83-91) percorre l'opera attraverso lo studio della rappresentazione della fisicità corporale e traccia un percorso che dal corpo in decomposizione, simbolo della difficoltà esistenziale, arriva al corpo ricomposto, più sognato che realizzato, fino al corpo sacrificato per poi risorgere, metaforicamente, a nuova vita.

3 La coerenza tematica che percorre l'opera di NDiaye è accompagnata da una consapevolezza stilistica sorprendente. Così Lydie MOUDILENo dimostra che la competenza linguistica permette alla scrittrice d'indagare l'anima dei personaggi mettendone a nudo le dinamiche e realtà (L'Excellent français de Marie Ndiaye, pp. 25-38). Christine CONNAN-PINTADO si concentra sui testi scritti per ragazzi e dimostra come vi si ritrovi intatta «la complexité inquiétante des écrits pour adultes» e la difficile linea di demarcazione che separa la realtà dal meraviglioso (L'Univers étrange et familier de Marie Ndiaye, pp. 39-52). La scrittura è al centro anche del saggio che Marie-Claire BARNET dedica a Autoportrait en vert, racconto autofinzionale nel quale la scrittrice gioca con i generi e li piega alle sue esigenze (Déroute d'un "Autoportrait en vert" (mère): vers l'errance de Marie Ndiaye, pp.153-170). Sullo stesso testo scrive Shirley JORDAN concentrandosi sulle immagini fotografiche che non assolvono il ruolo di illustrazione o di suscitare la scrittura come in En famille, ma contribuiscono a creare un testo instabile. Il rapporto tra testo e immagine è al centro del saggio di Marinella TERMITE su La Naufragée (1999), scritto per la collana «Musées secrets» di Flohic. L'autrice compara la scelta dei colori e la persistente presenza di sfumature sfocate che sfociano nell'indefinito, con la rappresentazione della realtà nei testi narrativi (pp. 53-63). 